\title{
Spatial accessibility of public transport in Australian cities: Does it relieve or entrench social and economic inequality?
}

\author{
Jan Scheurer \\ Curtin University/RMIT University \\ jan.scheurer@rmit.edu.au
}

\author{
Carey Curtis \\ Curtin University \\ c.curtis@curtin.edu.au
}

\section{Sam McLeod \\ Curtin University \\ sam.mcleod@curtin.edu.au}

\begin{abstract}
City planning in Australian cities has seen a gradual shift in approach, away from planning to facilitate mobility by car in the post-war period toward planning for land-use/public transport integration. By assessing the supply of public transport for city accessibility, a considerable variation within each city can be seen. Of interest is the extent to which there is a relationship between the quality of public transport accessibility and the spatial distribution of socioeconomic advantage and disadvantage. This paper examines this issue by mapping spatial data on socioeconomic disadvantage and advantage against indicators of public transport accessibility. The findings show that Australian cities are characterized by a significant level of spatially manifested socioeconomic inequality exacerbated by transport disadvantage. It is argued that a coincidence of public transport infrastructure and service improvements as well as urban intensification and housing affordability policies are required to counteract these trends.
\end{abstract}

Keywords: Public transport accessibility; socioeconomic advantage and disadvantage

\section{Introduction}

This paper seeks to investigate the spatial context between public transport accessibility and relative social and economic advantage and disadvantage in Australia's five largest capital cities. Of interest is the question whether recent trends of inner urban gentrification have contributed to the spatial concentration of lower-income households in outer suburban areas where they are also transport disadvantaged, both in terms of marginal or non-existing public transport options and in terms of a peripheral position in relation to metropolitan employment markets, translating into excessively long car commutes. Conversely, we will examine to what extent higher-income households show a tendency to concentrate in areas where the presence of a variety of transport options produce superior accessibility outcomes and

Copyright 2017 Jan Scheurer, Carey Curtis \& Sam McLeod

http://dx.doi.org/10.5198/jtlu.2017.1097

ISSN: 1938-7849 | Licensed under the Creative Commons Attribution - Noncommercial License 3.0

The Journal of Transport and Land Use is the official journal of the World Society for Transport and Land Use (WSTLUR) and is published and sponsored by the University of Minnesota Center for Transportation Studies. This paper is also published with additional sponsorship from WSTLUR. 
thus add a greater degree of motility (Kaufmann, 2011) to the suite of items constituting socioeconomic advantage for this group.

For this purpose, we superimpose public transport accessibility measures from the Spatial Network Analysis for Multimodal Urban Transport Systems (SNAMUTS) indexes (Curtis and Scheurer, 2016) on the Socio-Economic Indexes for Areas (SEIFA) measures compiled from census data by the Australian Bureau of Statistics (ABS). A historical overview will introduce the context and review existing literature, while a concluding discussion will reflect on some implications of the findings for policy makers.

\section{Historical overview}

As car ownership proliferated among Australian urban households after 1945, the geographical distribution of population and activities relative to public transport infrastructure underwent a profound change. Individual motorized mobility enabled car-owning households to locate in and thus power the growth of suburban areas with only marginal provision of public transport without adverse impact on their access to the city's opportunities. For people with higher socioeconomic status, the post-war, car-oriented, low-density residential suburbs were often perceived as offering greater amenity than the generally denser, older, mixed-use housing stock associated with the catchments of train stations or long-established tram and bus routes. This outward movement of privileged urban dwellers followed a trend that had already begun in the $19^{\text {th }}$ century and can be traced to the provision of trains and trams as agents of suburban development in the pre-automobile age, and the proliferation of individual home and land ownership as a widespread form of suburban tenure (Dodson \& Sipe, 2008). As a consequence, public transport modes of travel as well as the neighborhoods surrounding them, including many inner suburban areas, tended to become the domain of more disadvantaged socioeconomic groups. Good public transport accessibility in a spatial sense thus often coincided with concentrations of less wealthy people with low levels of car ownership and a greater dependence on public transport to access everyday activities. Indeed, the primary motivation of public transport agencies was to provide services as a welfare option, catering for those who could not afford a car.

Since the 1980s, with the post-war economic boom subsiding and car ownership in Australian cities reaching saturation levels, a countervailing trend has seen a return of affluent population groups into gentrifying inner urban areas, where the amenity and diversity were now valued more positively by upcoming generations and were forming a symbiotic relationship with the emerging knowledge economy (Newman \& Kenworthy, 2015; Florida, 2017). Consequently, disadvantaged groups gradually found themselves priced out of such neighborhoods and distributed into suburbs usually at a greater distance from metropolitan centers. As a consequence of earlier agency decisions on approaches to public transport supply in the face of rising car ownership as well as their more peripheral geographical location, these suburbs were less accessible by public transport. To compensate for this shortfall, disadvantaged households typically became car owners, though often of fewer (per household member) and/or lowerquality cars than their counterparts in more affluent car-dependent suburbs.

These trends resulted in a more complex spatial relationship of socioeconomic advantage/disadvantage and public transport accessibility. For North American cities, such characteristics have been documented in detail by Florida (2017), who traces the residential choices of the creative class, a close though not exact proxy for social and economic advantage, in large US, UK and Canadian cities over time. Florida concludes that the shift of advantaged groups back into inner urban areas and the subsequent increasing concentration of disadvantage in suburban areas takes on a range of archetypical spatial patterns, or patchworks, that vary from city to city and are linked to a metropolitan areas position on the global and national city hierarchy as well as historical, geographical and economic conditions. In this paper, we explore whether and to what extent Australian capital cities are developing similarly distinctive 
and city-specific new spatial patchworks of socioeconomic advantage and disadvantage.

\section{Transport policy and socioeconomic disadvantage}

The nexus between transport policy and socioeconomic disadvantage did not attract broad research interest in the Australian context until the mid-2000s. Practical solutions to address transport disadvantage as a matter of socioeconomic equity tended towards a liberal model (Smyth, 2007), favoring approaches that centered on individual rather than collective, system-wide societal interventions. As such, it is not surprising that even as a social policy objective (not to speak of as a transport policy objective), the comprehensive provision of high-quality public transport has traditionally held a lower priority than the facilitation of universal and affordable access to the private car. In this context, individually owned automobiles were regarded as ostensible levelers of socioeconomically derived inequities in spatial accessibility, even though the provision of road infrastructure and enabling planning systems also constitutes a highly centralized political and financial choice on behalf of governments.

The scarcity of scholarly work was complemented by a widespread disconnect between practitioners in the fields of social and transport policy, and the resulting relative obliviousness to each other's policy objectives (Stanley \& Lucas, 2008). Social benefits did not habitually feature in the evaluation of transport infrastructure projects, an omission that routinely led to a lower valuation of public transport proposals and an excessive focus on mobility rather than accessibility outcomes. Thus, when Australian city planners turned to an interest in re-urbanization post-1970s, the mindset among policy makers considered residential location disadvantage of limited relevance to social outcomes since it could be overcome by private mobility to achieve access to opportunities, provided the barriers to car ownership and use, financial and otherwise, remained low. Dodson (2007) summarizes how this complacency led to a range of outcomes that exacerbated spatial inequities in Australian cities. Firstly, private cars are, and will remain, unavailable to significant population groups unable to drive (the young, the old and the disabled) or to afford them. Secondly, faced with increasing shortages of affordable housing in areas with greater transport choices, low-income households are forced to trade off residential affordability and (public) transport accessibility. For households locating in poorly accessible areas, this translates into high costs of car ownership and mounting vulnerability to rising fuel costs. At the same time, the decline of traditional industrial employment in suburban areas and the ongoing concentration of knowledge-based employment in central areas reduces the number of jobs (or the number of secure or skills-matched jobs) that can be reached within a reasonable commuting time.

Currie et al. (2009) examined the spatial and individual patterns of transport disadvantage in more detail and found that transport-disadvantaged households in outer suburban areas of Melbourne with poor public transport divided into two groups, which the authors initially described as zero car ownership and forced car ownership households. Zero car ownership households would typically select a residential location in walking distance to shops and services and experience disadvantage by facing constraints to independently access opportunities beyond this spatial range. Forced car ownership households are assumed to spend a disproportionate amount of their limited incomes on car ownership and operation, trading off this disadvantage against the opportunity for home ownership in an affordable (but usually highly car-dependent) area. However, after interviewing a range of households in both categories and finding that both groups exercise considerable agency on their residential location as well as their transport choices, Currie et al. (2010) depart from the earlier terminology of zero car and forced car ownership and simply speak of social exclusion due to a variety of factors ranging from lack of opportunity to travel to desired destinations, pressures on the household budget from private vehicle costs and the subsequent need to cut other expenses, and detrimental impacts on wellbeing resulting from 
time-poor lifestyles exacerbated by long daily commutes as well as excessive periods spent driving for non-commuting purposes. Critically, this research departs from the notion that it is predominantly the lack of a private vehicle that leads to transport-related social disadvantage in Australian cities; disadvantage is also present in low-income, car-owning households for different though not unrelated reasons.

De Vos, Schwanen, Van Acker, and Witlox (2013) link this sense of transport inequality to the concept of motility (the capacity for being mobile, see also Kaufmann, 2011), which from a spatial and transport networks perspective peaks in higher-density, centrally located neighborhoods and drops off towards the lower-density fringes of a metropolis. However, like Currie et al. (2010) and Delbosc and Currie (2011) they point to a degree of residential self-selection exercised even by lower-income households, reflecting their preferred travel choices, an effect that relativizes (to an extent) the truism offered by Florida (2017, p. 150) that "the rich live where they choose, and the poor live where they can."

\section{$4 \quad$ Research approach}

Australian city planning, like other new world cities, has witnessed a change in policy focus over the decades: from post war planning where individual/household accessibility was to be achieved by planning suburbs and the city to facilitate car-based mobility to the decades since the 1990s where planners have shifted to planning the city around ideas of land-use/public transport integration (Curtis, 2015). While progress is slow, given long lead times for transport infrastructure and development and also that Australian cities have an urban structure entrenched in car mobility, the investment in public transport can be assessed from an accessibility perspective. The authors (Curtis \& Scheurer, 2016) demonstrate this for the major Australian cities drawing upon their SNAMUTS tool. It can be seen that the supply of public transport delivers variable accessibility across each metropolitan region and generally much favors more centrally located parts of the city over the periphery. This centripetal pattern generally also holds true for car accessibility in relation to jobs, particularly in light of Australian cities having developed few of the major tertiary employment clusters in suburban areas that are common, for example, in many US cities. As shown in investigations on effective job density for commuters (SGS Economics and Planning, 2015), the number and range of jobs accessible by car consistently remain highest for residents in central areas and lowest at the periphery of Australian agglomerations.

In this paper we take the analysis further by quantifying the extent to which more advantaged groups are concentrated in public transport-accessible neighborhoods, and to which more disadvantaged groups are located away from good public transport access. Our focus is on Australias five largest cities at the time of the 2011 census. While it would be desirable to examine accessibility and socioeconomic trends along a timeline to document the process of socioeconomic change in greater depth and spatial granularity, doing so would require a far greater collection of data in both areas and remains outside the scope of this contribution.

For socioeconomic data, we draw on spatially detailed data on socioeconomic advantage and disadvantage from the ABS SEIFA and correlate this with findings on public transport accessibility from the SNAMUTS outputs. Our aim is to identify the geographical distribution of statistical areas (SA1) in the highest and lowest average socioeconomic status categories (SEIFA quintiles) in relation to public transport accessibility, and to construct a narrative for each city about the opportunities and constraints governing patterns of household location.

The SEIFA have been compiled from ABS census data at five-year intervals since 1986 (Pink, 2013). The Index of Relative Socio-Economic Advantage and Disadvantage (IRSAD) used in this paper represents one out of four published SEIFA indexes and classifies SA1 in relative terms on the basis of a weighted average of 25 separate census measures covering income, education, employment, occupation, housing and other variables. Results are expressed along an arbitrary numerical scale that is standardized 
for a score of 1000 to represent the mean value across the sample, and for a standard deviation of 100 with higher scores indicating greater area-based socioeconomic advantage/lower disadvantage and lower scores indicating lower advantage/greater disadvantage. For ease of interpretation, the ABS recommends the representation of SEIFA results in quantile groups rather than absolute values (ibid). In this paper, IRSAD scores are differentiated by five residential population quintiles.

Two modified SNAMUTS indicators are utilized in this assessment. The residential coverage indicator is a variation of the network coverage indicator used widely in SNAMUTS and other accessibility analyses (Curtin \& Scheurer, 2016). It depicts all residents that are located either within an 800-metre radius of a rail station or ferry terminal, or within a 400-metre linear corridor around a tram or bus route that meets the defined minimum service standard. ${ }^{1}$ This figure is expressed as a percentage of the total population of the metropolitan area (in the average column), and as a percentage of the metropolitan population that falls into the SEIFA quintile under consideration. Note that the figures differ from the network coverage figures shown in other SNAMUTS publications (such as Curtis \& Scheurer, 2016), since the location of jobs is excluded from this count.

The contour catchment index expresses an approximation of the percentage of metropolitan residents and jobs that can be reached from a reference point within a public transport journey of $30 \mathrm{~min}$ utes or less. These scores are influenced by the speed, frequency and network density of public transport as well as the spatial concentration and density of residents and jobs within each contour. The index is based on the catchment areas of a suite of defined activity nodes relating to the hierarchy of central places in each city. Each SA1 within the residential coverage areas (as defined above) is allocated to one walkable activity node radius ( 800 meters for rail stations or ferry terminals) or corridor (400 meters either side along bus or tram routes), or in some cases, to two or more overlapping radii/corridors, and carries the same contour catchment score as all other SA1 within the same radius/corridor (or same configuration of overlapping radii/corridors). The figures in Table 1 depict the average 30-minute contour catchment score of all SA1 within the residential coverage areas, and the average 30-minute contour catchment score of all SA1 whose SEIFA scores fall within the respective quintile. Note that the average results in this table differ from those in other publications (such as Curtin \& Scheurer, 2016) as they only refer to those SA1 within activity node catchments where there is a residential population, and as they determine averages across all SA1 rather than across the sample of activity nodes.

\section{$5 \quad$ Findings}

Table 1 shows some basic data on the five selected cities concerning total metropolitan population and activity density as well as the range and rough extent of public transport modes available.

\footnotetext{
${ }^{1}$ The minimum service standard requires a rail or ferry route to be operated seven days a week, at a frequency of at least every 30 minutes during the inter-peak period (between 10.00 and 15.00) on weekdays. Buses and trams have to be operated at least every 20 minutes during the weekday inter-peak period, and at least every 30 minutes during the day on Saturdays, Sundays and public holidays.
} 
Table 1: Overview of population/density and basic public transport supply data in five Australian cities

\begin{tabular}{|c|c|c|c|c|c|}
\hline City & Melbourne & Sydney & Adelaide & Brisbane & Perth \\
\hline $\begin{array}{l}\text { Metropolitan } \\
\text { population (2011) }\end{array}$ & $4.00 \mathrm{~m}$ & $4.39 \mathrm{~m}$ & $1.23 \mathrm{~m}$ & $2.01 \mathrm{~m}$ & $1.73 \mathrm{~m}$ \\
\hline $\begin{array}{l}\text { Density (per ha of } \\
\text { urbanized land) of } \\
\text { residents and jobs } \\
\text { (2011) }\end{array}$ & 28.3 & 36.6 & 24.2 & 23.8 & 22.9 \\
\hline $\begin{array}{l}\text { Public transport } \\
\text { modes provided }\end{array}$ & $\begin{array}{l}\text { - Electrified } \\
\text { suburban rail } \\
\text { - Tram (mature } \\
\text { network) } \\
\text { - Bus }\end{array}$ & $\begin{array}{l}\text { - Electrified } \\
\text { suburban rail } \\
\text { - Tram (single } \\
\text { route) } \\
\text { - Bus } \\
\text { - Ferry (selected } \\
\text { routes) } \\
\end{array}$ & $\begin{array}{l}\text { - Non-electri- } \\
\text { fied suburban } \\
\text { rail } \\
\text { - Tram (single } \\
\text { route) } \\
\text { - Bus }\end{array}$ & $\begin{array}{l}\text { - Electrified } \\
\text { suburban rail } \\
\text { - Bus } \\
\text { - Ferry (selected } \\
\text { routes) }\end{array}$ & $\begin{array}{l}\text { - } \text { Electrified } \\
\text { suburban rail } \\
\text { - } \text { Bus } \\
\text { - Ferry (single } \\
\text { route) }\end{array}$ \\
\hline $\begin{array}{l}\text { Heavy rail stations per } \\
100,000 \text { inhabitants } \\
(2011)^{2}\end{array}$ & 5.3 & 4.0 & 6.4 & 5.5 & 3.9 \\
\hline $\begin{array}{l}\text { Integrated fares across } \\
\text { all PT modes }\end{array}$ & Yes & No & Yes & Yes & Yes \\
\hline
\end{tabular}

Source: Curtis and Scheurer, 2016

Table 2 shows the average results for two SNAMUTS indicators categorized by five SEIFA categories: the lowest and highest quintile depicted in the maps shown further below, and the intermediate second, third and fourth quintile with a lower ranking indicating greater disadvantage. All figures relate to the census year 2011.

Table 2: Overview of residential network coverage and average 30-minute contour catchment (in percentage of all metropolitan residents and jobs), metropolitan total/averages, and per SEIFA quintile (lowest quintile is most disadvantaged) in each of Australia’s five largest capital cities

\begin{tabular}{|c|l|c|c|c|c|c|c|}
\hline \multirow{2}{*}{ City } & \multicolumn{1}{|c|}{ Index } & $\begin{array}{c}\text { All } \\
\text { Quintiles }\end{array}$ & $\begin{array}{c}\text { Lowest } \\
\text { Quintile }\end{array}$ & $\begin{array}{c}\text { 2nd } \\
\text { Quintile }\end{array}$ & $\begin{array}{c}\text { 3rd } \\
\text { Quintile }\end{array}$ & $\begin{array}{c}\text { 4th } \\
\text { Quintile }\end{array}$ & $\begin{array}{c}\text { Highest } \\
\text { Quintile }\end{array}$ \\
\hline \multirow{2}{*}{ Melbourne } & Residential Coverage & $46.1 \%$ & $41 \%$ & $34 \%$ & $45 \%$ & $50 \%$ & $61 \%$ \\
\cline { 2 - 8 } & Average Contour Catchment & $7.0 \%$ & $4.3 \%$ & $4.9 \%$ & $6.6 \%$ & $8.0 \%$ & $9.5 \%$ \\
\hline \multirow{2}{*}{ Sydney } & Residential Coverage & $53.3 \%$ & $55 \%$ & $51 \%$ & $58 \%$ & $58 \%$ & $45 \%$ \\
\cline { 2 - 8 } & Average Contour Catchment & $8.3 \%$ & $7.4 \%$ & $8.5 \%$ & $8.9 \%$ & $8.5 \%$ & $8.0 \%$ \\
\hline \multirow{2}{*}{ Adelaide } & Residential Coverage & $53.4 \%$ & $53 \%$ & $57 \%$ & $60 \%$ & $52 \%$ & $44 \%$ \\
\cline { 2 - 8 } & Average Contour Catchment & $8.8 \%$ & $7.0 \%$ & $8.4 \%$ & $9.4 \%$ & $9.2 \%$ & $10.2 \%$ \\
\hline \multirow{2}{*}{ Brisbane } & Residential Coverage & $35.8 \%$ & $26 \%$ & $33 \%$ & $39 \%$ & $43 \%$ & $38 \%$ \\
\cline { 2 - 8 } & Average Contour Catchment & $8.8 \%$ & $4.3 \%$ & $7.3 \%$ & $9.0 \%$ & $10.5 \%$ & $9.0 \%$ \\
\hline \multirow{2}{*}{ Perth } & Residential Coverage & $35.6 \%$ & $37 \%$ & $39 \%$ & $36 \%$ & $37 \%$ & $29 \%$ \\
\cline { 2 - 8 } & Average Contour Catchment & $10.2 \%$ & $6.8 \%$ & $10.2 \%$ & $10.9 \%$ & $11.5 \%$ & $12.0 \%$ \\
\hline
\end{tabular}

The results reveal a significant variation between the five Australian capital cities regarding the spatial distribution of socioeconomic advantage and disadvantage, and quality of public transport accessibility.

\footnotetext{
${ }^{2}$ With services at the SNAMUTS minimum standard or better (see above).
} 


\subsection{Melbourne}

In Melbourne, the most advantaged twenty per cent of the population are characterized by the highest percentage across all quintiles in all five cities with walking-distance access to public transport (residential network coverage) (Table 1). As relative disadvantage increases, walkable coverage of public transport and average 30-minute contour catchments decline. Only in the lowest quintile does the coverage figure rise slightly in comparison with the second quintile, but it is still below the metropolitan average.

Map 1 shows the geographical distribution of the population's socioeconomic advantage and disadvantage in relation to public transport coverage and average 30-minute contour catchment size of residential areas in Melbourne. In this analysis only the top and bottom quintiles are shown to discern the patterns more clearly.

Conspicuously, for areas with public transport coverage at the minimum standard there is a clear pattern whereby the most advantaged areas concentrate in inner suburbs, compared to the least advantaged areas, which are predominantly located in the outer suburbs. The most advantaged areas are in the municipalities of Boroondara, Stonnington, Port Phillip, Glen Eira and Bayside in the city's inner east and southeast - districts that have generally been known as relatively wealthy since they were first urbanized. But significant parts of traditional inner-urban working-class districts such as Fitzroy and Richmond, located immediately north and east of the CBD, can also be found in the highest SEIFA quintile. The high socioeconomic status of these areas thus shows traces both of long-standing affluence and of recent inner-urban gentrification, as documented over a 25-year period by Loader (2013) with a record of sizeable concentrations of disadvantaged households in most of Melbourne's inner-ring suburbs as recently as 1986. In contrast, and echoing the findings in Currie (2010), Melbourne's most disadvantaged areas today are concentrated in the western, northern and southeastern outer suburbs (Wyndham, Melton, Brimbank, Hume, Whittlesea, Dandenong, Casey, Frankston) whose public transport accessibility performance is low primarily due to their distance from central areas, and where walkable access to quality public transport from residential neighborhoods is largely limited to the station catchments of the relatively widely spaced rail corridors. In some cases, pockets of socioeconomic advantage can also be found at the urban fringe, particularly surrounding the Yarra Valley in the northeast (Manningham, Nillumbik, Maroondah) and in recent high-end master-planned estates such as Sanctuary Lakes and Point Cook in Wyndham (southwest), Laurimar in Whittlesea (northeast) or Berwick Springs in Casey (southeast). In the broader outer eastern corridors of the Ringwood to Lilydale and (to a lesser extent) the Ringwood to Belgrave rail branches, there is a clear tendency for advantaged groups to locate outside the walkable station catchments and for disadvantaged groups to locate inside them - but this pattern does not appear to be replicated elsewhere in metropolitan Melbourne.

Melbourne's socioeconomic and accessibility geography thus illustrates some of the patterns hypothesized earlier in this paper - a trend for advantaged groups to consolidate in and capitalize on public transport-accessible inner areas, and a trend for disadvantaged groups to concentrate in outer suburban areas (mostly away from scenic waterfronts and river valleys) where public transport access is patchy. 


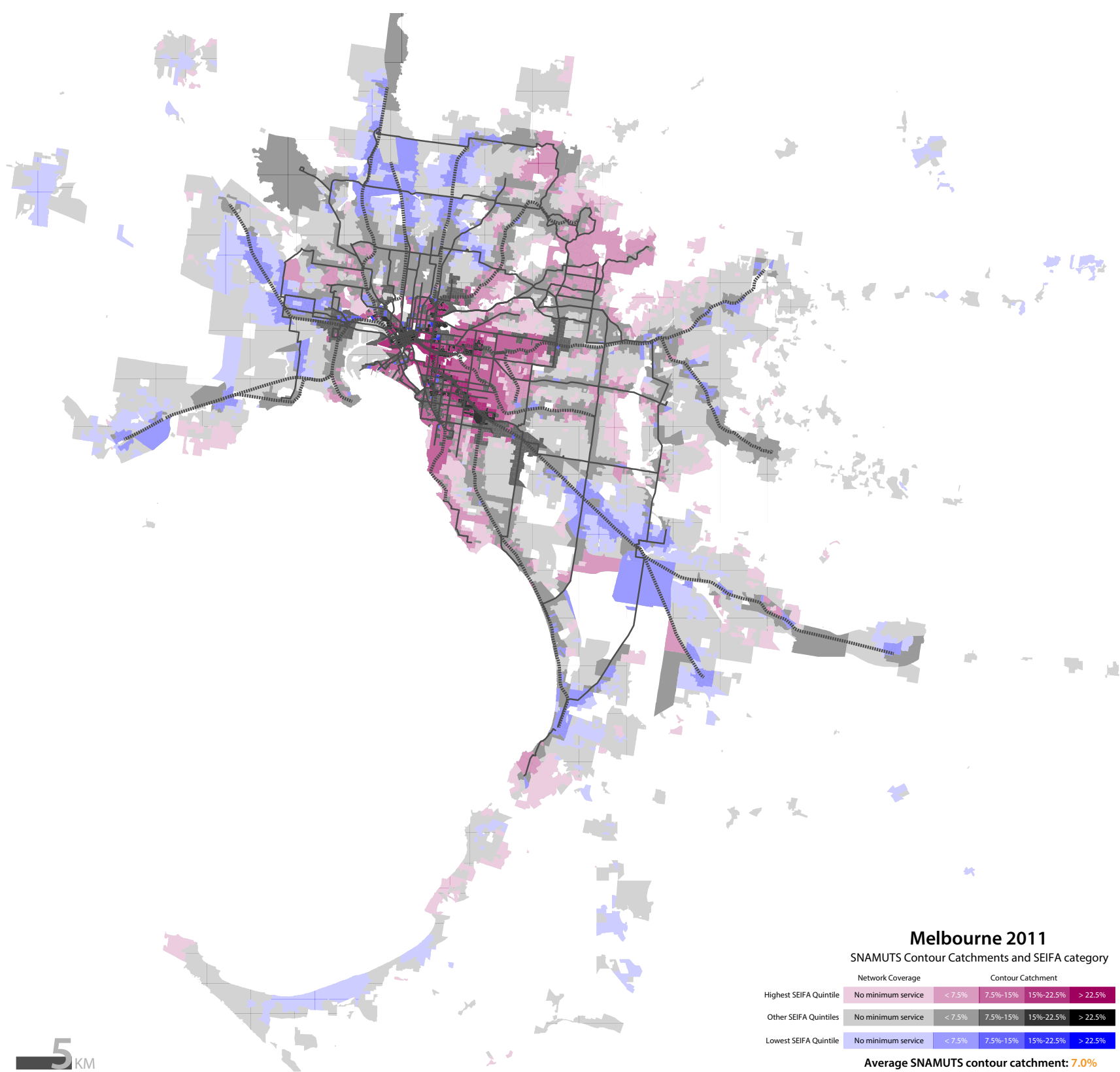

Map 1: Spatial distribution of residential population in the highest and lowest SEIFA quintiles in relation to public transport network coverage and average 30-minute contour catchments in metropolitan Melbourne (2011)

\subsection{Sydney}

In Sydney (Map 2), a different spatial pattern to Melbourne emerges. The city's most socially and economically advantaged areas are almost exclusively located on the north shore of the harbor, where only the station areas around the rail lines and the Pittwater Road bus corridor along the northern beaches have walkable access to public transport, and in the inner eastern suburbs where (mostly bus-based) public transport coverage is more universal but where a convoluted topography around inlets and peninsulas generates natural barriers to good accessibility. As a result, Sydney's most advantaged residential 
areas are characterized by the lowest level of network coverage and the second lowest average 30-minute contour catchments. The attractiveness of scenic waterfront or edge-of-national-park locations, a phenomenon already observed in Melbourne (though at a much lower rate), appears to dominate the location choices of affluent Sydneysiders and has limited correspondence with public transport accessibility performance.

The most disadvantaged socioeconomic groups show a strong geographical concentration in the western suburbs, particularly Canterbury-Bankstown, Liverpool, Cumberland, Fairfield, Campbelltown, Blacktown and Penrith. These areas have a public transport network structure comparable to that of Melbourne's outer suburbs, with a limited number of rail and bus corridors providing walkingdistance access to some residents while leaving large patches of urbanized land beyond these catchments.

Sydney's inner west and south falls generally in the middle SEIFA categories, which is not necessarily a sign that gentrification was not occurring at a level comparable to that in Melbourne's Fitzroy or Richmond, but rather that average socioeconomic advantage in these places has not (yet) reached a similar level to that in more traditionally affluent areas north of the harbor or east of the CBD. Lastly, like in Melbourne there are some conspicuous pockets of advantage in fringe growth areas, particularly around Rouse Hill in the northwest and in Sutherland Shire in the south.

Overall, Sydney's average residential network coverage and accessibility performance (as measured by average 30-minute contour catchments) vary much less between socioeconomic groups than in Melbourne; the most privileged groups are not at a tangible advantage over others in this respect. However, on the residential network coverage measure, Sydney's metropolitan average as well as the results for each SEIFA quintile occupy either the first or second rank among the five Australian cities sampled here. 


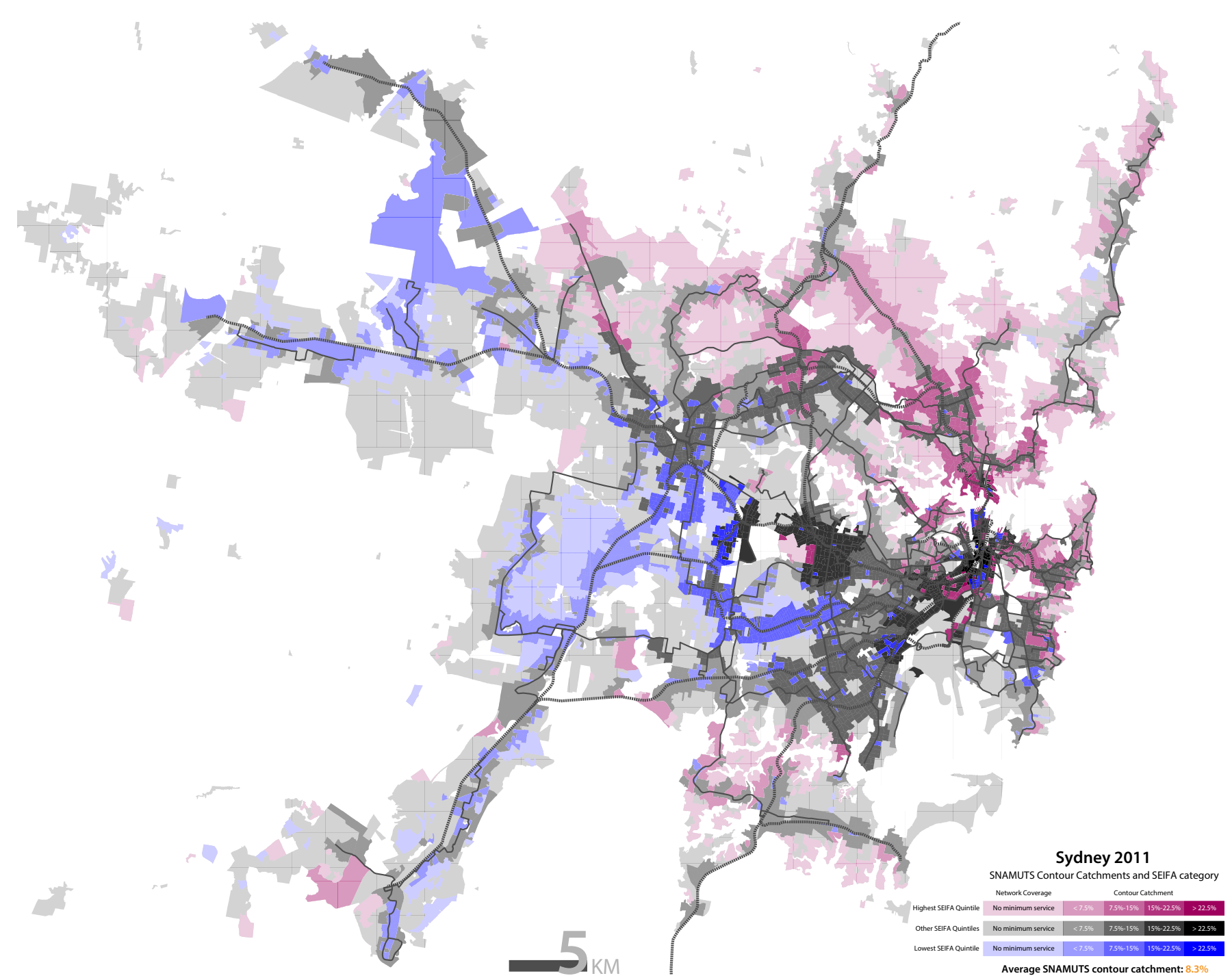

Map 2: Spatial distribution of residential population in the highest and lowest SEIFA quintiles in relation to public transport network coverage and average 30-minute contour catchments in metropolitan Sydney (2011)

\subsection{Adelaide}

A similar conclusion can be made for Adelaide, which has the highest average level of residential network coverage in the sample alongside Sydney, thanks to a relatively generous allocation of operational resources and a resulting greater bus network density than in other cities (Curtin \& Scheurer, 2016). Like Sydney and unlike Melbourne, Adelaide shows a drop in average network coverage for the most advantaged groups. As illustrated in Map 3, residents in the highest SEIFA quintile tend to predominantly live adjacent to or across the Adelaide Hills, which form a natural boundary to the contiguously urbanized area in the city's east, and, albeit to a much lower extent than in Sydney or even Melbourne, along the coastline in the west. Pockets of socioeconomic advantage also dominate Adelaide's inner suburbs to the north, east and south, where public transport coverage is almost universal. The most disadvantaged groups in Adelaide scatter across the mid-northern and northwestern suburbs (with relatively good though mostly bus-based geographical public transport coverage), and the outer suburban corridors 
around Salisbury-Elizabeth in the north and Noarlunga in the south (with walkable access to quality public transport largely limited to the train station catchments). A high-end greenfield development away from more established affluent neighborhoods and, untypically in the Australian context, with good public transport network coverage, can be found in Mawson Lakes in the mid-northern suburbs.

Average 30-minute contour catchments increase almost consistently in line with socioeconomic status among residential areas in Adelaide, supporting the hypothesis that for those residents who do locate near public transport at the minimum standard, a higher standard of public transport accessibility forms part of socioeconomic privilege (and vice versa).

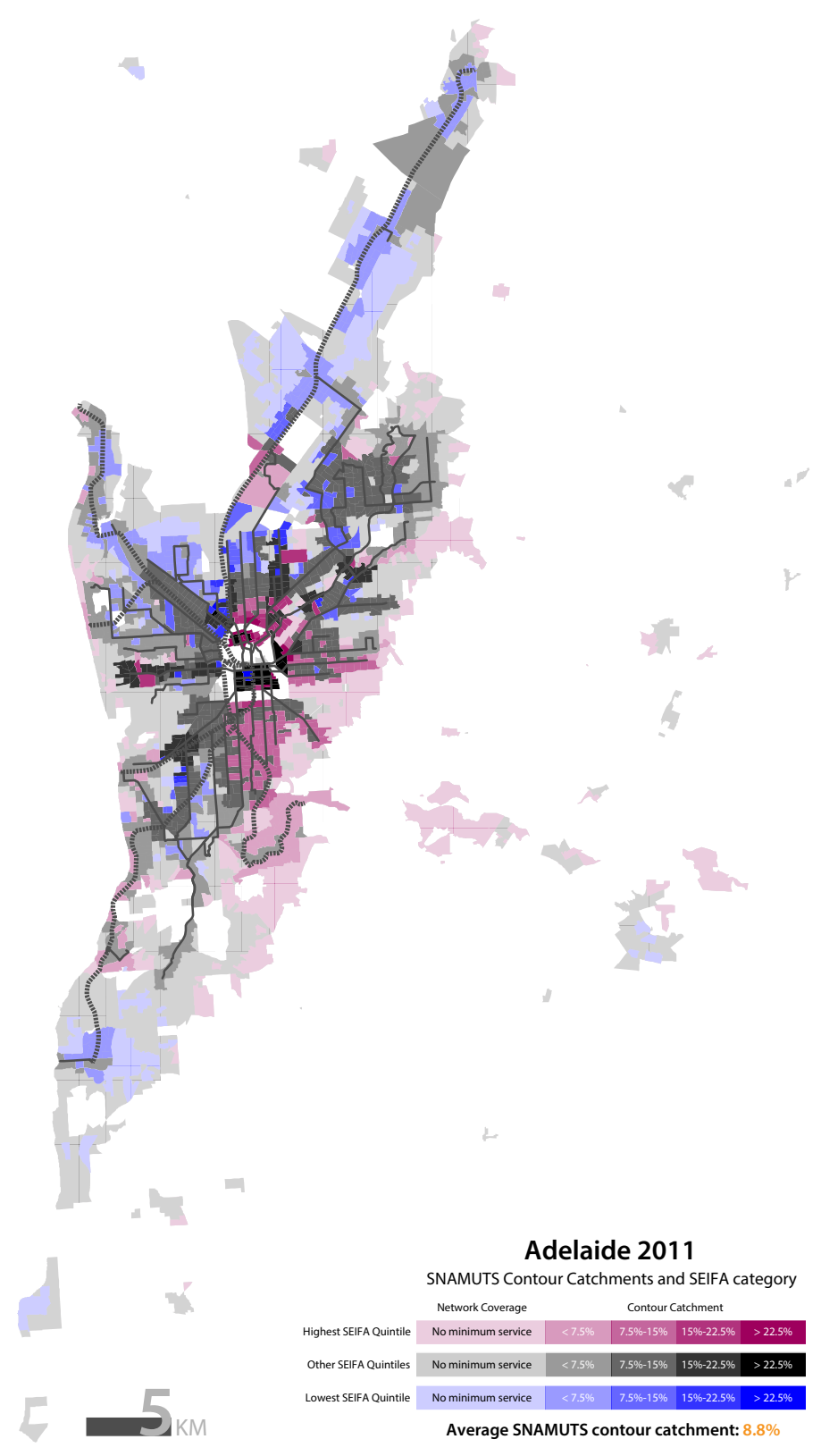

Map 3: Spatial distribution of residential population in the highest and lowest SEIFA quintiles, in relation to public transport network coverage and average 30-minute contour catchments in metropolitan Adelaide (2011) 


\subsection{Brisbane}

Brisbane's picture for socioeconomic advantage by residential network coverage is also closely aligned with the overarching hypothesis, showing a relationship where the more disadvantaged are also residing in less public transport-accessible areas, but as with Sydney this trend is broken with the least disadvantaged quintile. Brisbane's most disadvantaged residents (by SEIFA quintile) are also characterized by both the lowest rate of residential network coverage and the equal smallest (alongside Melbourne) average 30-minute contour catchments of all SEIFA groups across the five capital cities (Table 1). These areas are almost exclusively located in the suburban municipalities of Ipswich (southwest), Logan (southeast) and Moreton Bay (north; Map 4) and are accessed by a limited number of train lines, but few or no bus services that meet the SNAMUTS minimum standard. Residential neighborhoods for the most advantaged groups tend to agglomerate in the city's west, where a chain of scenic hills borders the urbanized area, scattered across inner suburbs particularly along the Brisbane River, and along the coastline in Redland to the east of the city. In the case of the Ferny Grove rail line in the mid-northwest, the most affluent neighborhoods tend to agglomerate at some distance, outside the walkable station catchments, from the actual rail corridor. Recent greenfield growth areas with a high socioeconomic status can be found in a number of locations, including Springfield-Augustine Heights in the southwest, and North Lakes-Mango Hill in the north. Like in Sydney, average network coverage and accessibility performance (average contour catchment) peak in the middle of the SEIFA spectrum rather than with either the lowest or the highest quintile. 


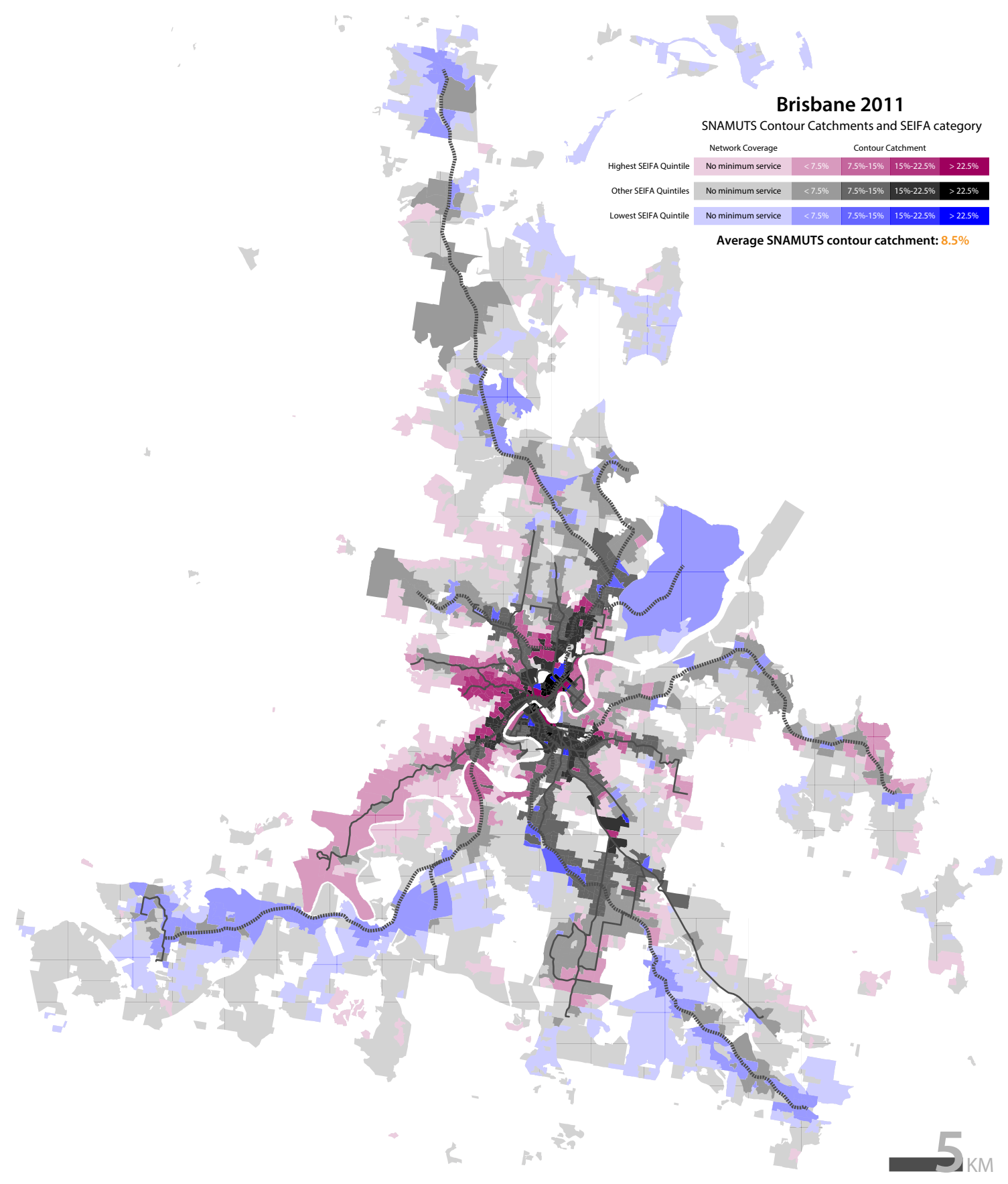

Map 4: Spatial distribution of residential population in the highest and lowest SEIFA quintiles, in relation to public transport network coverage and average 30-minute contour catchments in metropolitan Brisbane (2011)

\subsection{Perth}

Like in Brisbane, most Perth residents are excluded from easy access to quality public transport near their homes: services at the SNAMUTS minimum standard in walking distance cover only just over onethird of residential neighborhoods (by population). Residential network coverage varies little between the SEIFA quintiles, the exception being the highest socioeconomic group who have poorer coverage 
(while those residents in the highest quintile who do have coverage enjoy the largest average 30-minute contour catchment across the five-city sample). As shown in Map 5, these residents tend to agglomerate around the shores of the Swan River in the inner west (where public transport coverage varies) and along the Indian Ocean coast to the north (where quality public transport coverage is largely absent as the rail corridor runs about three kilometers inland). Further pockets of privileged neighborhoods can be found in the Perth Hills (outer east) around Kalamunda, and in greenfield growth areas at the urban fringe (in the northeast at Ellenbrook, south at Southern Rivers and Aubin Grove, and southwest at Secret Harbour). Residential areas with the greatest socioeconomic disadvantage show a similar trend to geographic concentration towards selected outer suburbs as in the other capital cities. In Perth, this mainly concerns Mirrabooka-Alexander Heights in the north, Bayswater and Midland in the east, Gosnells and Armadale in the southeast, Hamilton Hill and Coolbellup in the mid-southwest, and Kwinana, Rockingham and Mandurah in the outer southwest. In these areas, public transport access at the SNAMUTS minimum standard is limited to the rail corridors and some feeder bus services, leaving sizeable spatial gaps between walkable catchment areas.

Average accessibility performance (contour catchments) in the residential neighborhoods that have quality public transport coverage grows in a linear fashion with growing socioeconomic status, starting from a conspicuously low level for the lowest SEIFA quintile (Table 1). Most public transport-covered affluent areas can be found in relatively close proximity to the central city and in particular along the Perth to Fremantle train line, where accessibility performance is inherently better than elsewhere. Most of the disadvantaged areas are located towards the outer termini of radial train lines away from the coast, with few attractive options for public transport movement in directions other than into and out of the central city. These characteristics tend to depress average 30-minute contour catchments. 


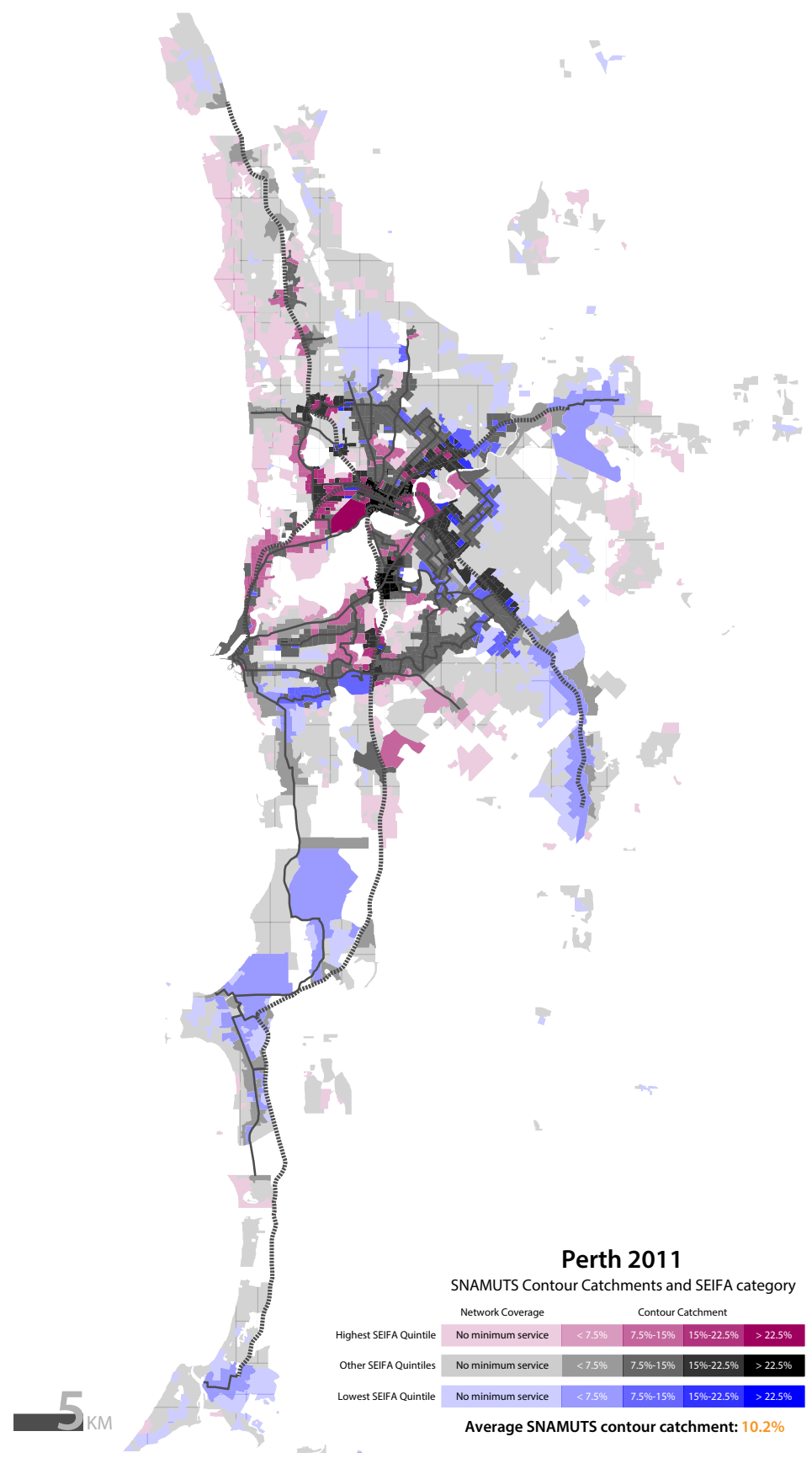

Map 5: Spatial distribution of residential population in the highest and lowest SEIFA quintiles, in relation to public transport network coverage and average 30-minute contour catchments in metropolitan Perth (2011)

\subsection{Summary}

All five Australian capital cities display an underlying trend for average socioeconomic status (as defined by SEIFA/IRSAD category) to increase in line with public transport accessibility measures including the geographical coverage of the network and the average reach of a 30-minute journey, though to a varying degree and with varying secondary intervening factors. All five cities also display highly discernible patterns of spatial stratification of residential areas between most advantaged and most disadvantaged 
groups, dividing cities into distinct socioeconomic sub-regions with limited geographical overlap.

Melbourne has the strongest correlation for socioeconomic advantage in neighborhoods to grow in a linear fashion with good public transport performance. In Sydney, the presence of many lower-accessibility, high-amenity waterfront locations leads to a marked drop in average access to public transport for the most advantaged neighborhoods. In Adelaide, the city with the lowest rate of public transport usage per capita per year among the sample (Curtin \& Scheurer, 2016), neighborhoods in the highest socioeconomic status bracket are also much less likely than the average to coincide with a minimum standard of public transport network coverage (see definition above). In Perth and Brisbane, only a minority of residential neighborhoods is located within walking access to public transport of this standard. Their distribution across socioeconomic categories is more even in Perth than in Brisbane, where the weakest average correlation with public transport accessibility across the sampled cities can be found for neighborhoods with lower socioeconomic status.

In summary, considering the hypothesis that more advantaged groups are concentrated in public transport-accessible neighborhoods, and more disadvantaged groups are not, we find that there is a nearuniversal tendency for disadvantaged groups, who usually experience considerable financial constraints on their location choices, to concentrate in selected but generally poorly accessible middle and outer suburban areas. These concentrations generally concern entire corridors or sub-regions, with socioeconomic disadvantage spreading relatively evenly across both the (public transport-accessible) walkable rail station catchments and their wider suburban hinterland. Conversely, for more advantaged groups, who are considered to be in a position to exercise greater choice over their residential location, there appear to be two concurrent patterns. Some of these residents (particularly in Melbourne) clearly seek to capitalize on the relatively good public transport accessibility in traditionally wealthy or recently gentrifying inner and middle suburban areas, while others (dominant in all sampled cities other than Melbourne) prefer the proximity of environmental attractors such as waterfronts or nature reserves where the quality of public transport accessibility does not seem to be a determining location choice criterion. Recurrent exceptions from these patterns, and thus instances where a greater sub-regional mix of socioeconomic groups occurs, concern the emergence of pockets of affluence in master-planned greenfield estates within otherwise more disadvantaged sub-regions, and the concentration of disadvantage in the walkable catchments of some suburban rail lines where neighborhoods beyond these catchments show greater advantage (Melbourne's Lilydale and Belgrave branches, Sydney's Cronulla branch and Brisbane’s Ferny Grove line). In contrast, no examples were found of outer suburban rail station catchments displaying tangibly greater socioeconomic advantage than the neighborhoods immediately surrounding them outside the walkable range, though this may change in the future as more dedicated transit-oriented urban intensification programs transform and diversify some of these places.

These Australian findings can be related to Florida's (2017) categorization of "patchwork metropolis"archetypes in a North American and UK context. Florida distinguishes between four types. In the first type, the (socioeconomically advantaged) creative class recolonizes the inner urban area while also continuing to occupy long-standing affluent suburban areas. In the second type, it remains concentrated in suburbs. In the third type, a strong spatial division occurs across both inner and outer urban areas between the creative class and the (socioeconomically disadvantaged) service/working class. In the fourth type, the creative class occupies pockets of affluence, usually in physically attractive locations such as coastlines or in proximity to clusters of high urban amenity, in an archipelago-like pattern.

Our findings show that all Australian capital cities display characteristics of Florida's third spatial archetype of a divided metropolis. Florida's first archetype, however, appears to also find expression particularly in Melbourne, where concentrations of socioeconomic disadvantage have mostly disappeared from inner urban areas, and to a lesser extent in Sydney, which alongside Adelaide and Perth also embodies the features of Florida's fourth archetype. It should be noted in this context that Florida's 
definition of "creative class" does not match the definition of socioeconomic advantage as expressed by the SEIFA index: while Florida contends that members of the creative class on average enjoy far greater levels of disposable income than members of the service and working classes, this is not necessarily the case consistently and may thus not be distributed evenly in a geographical sense. Further, it is plausible that during Australias economic boom in the mining and construction industries, still well under way during the reference year of our analysis (2011), favorable opportunities for wealth accumulation existed for some people whose occupations are more closely aligned with Florida's definition of the working or service class. This would also be reflected in the geographical distribution of the SEIFA categories for socioeconomic advantage and disadvantage.

\section{Discussion and conclusion}

In a detailed analysis of transport disadvantage, social exclusion and well-being across the metropolitan area of their native Melbourne, Delbosc and Currie (2011) differentiate between inner, outer, fringe and regional areas and conclude that transport disadvantage expresses itself more acutely with increasing distance from the city center, as spatial gaps (Currie, 2010) in public transport supply proliferate and the range of activities that can be reached by non-car modes diminishes. This leads to pressures on lowincome households in terms of financial burdens and time poverty associated with high car ownership and use, and/or to forgone opportunities for social and employment participation due to accessibility gaps. In this context, an ongoing trend for socially and economically disadvantaged groups to vacate public transport-accessible and walkable/cyclable inner areas due to gentrification effects in favor of more affordable urban fringe locations must be regarded as an entrenchment both of the geographical division of Australian cities along socioeconomic lines, and of the variegation of socioeconomic inequality experienced by the affected segments of the population.

Of interest is whether there is a role for integrated public transport and land-use planning to ameliorate the effects of socioeconomic inequality. Further, is it the case that current urban development trends, investment priorities and allocation of operational resources in Australian cities reflect this role? In Melbourne, opportunities for a better alignment of urban development to overcome car dependence and reducing socioeconomic inequality have been hampered by spatial mismatches between public transport infrastructure and activity centers as the metropolitan fringe underwent ongoing urbanization (Goodman \& Coote, 2007). Further, there is a relative absence of effective affordable housing policies that could enable a larger proportion of disadvantaged groups to move to, or remain in, inner suburban areas where a greater choice of transport options is available and pressures toward car ownership and use are diminished (Martel et al., 2013).

The notion of a greater range of options for urban movement over a greater geographical area reflects Newman and Kenworthy's (2015) call for the walking city and the transit city to spatially expand to reduce the dominance of the car in Australian cities and also reflects Florida's (2017) call for broad infrastructure investment to support urban clustering in a greater range of places. Yet, it is questionable whether current Australian public transport infrastructure and network development strategies are best suited to achieve this goal. New rail infrastructure in Australian cities in this decade generally focusses on the provision of additional radial lines through central areas to boost capacity (Melbourne, Sydney, Brisbane) and the outer extension of suburban lines to access fringe growth areas (all five cities sampled here). Important as these projects are to future-proof public transport in fast-growing metropolitan areas, they represent primarily a response to existing radial, suburb-to-CBD movement patterns rather than an attempt to assist public transport to expand into more multi-directional travel markets currently dominated by the car, such as work commutes and discretionary trips to inner urban destinations beyond the CBD (Scheurer, Curtis, \& McLeod, 2016). Furthermore, without urban intensification pro- 
grams including a significant component of affordable housing, it is unlikely that the accessibility gains achieved by improved public transport infrastructure in either central or outer suburban areas translate into a tangible broadening of residential location choices for more disadvantaged socioeconomic groups away from their current strongholds in outer suburban corridors.

\section{Acknowledgements}

SNAMUTS research in Australian cities was made possible through ARC Discovery Grant DP110104884, Spatial Network Analysis for Multimodal Urban Transport Systems: A Planning Decision Support Tool', and through collaborations with local and state government agencies in Western Australia and Victoria. 


\section{References}

Currie, G. (2010). Quantifying spatial gaps in public transport supply based on social needs. Journal of Transport Geography, 18, 31-41.

Currie, G., Richardson, T., Smyth, P., Vella-Brodrick, D., Hine, J., Lucas, K., Stanley, J., Morris, J., Kinnear, R., \& Stanley, J. (2009.) Investigating links between transport disadvantage, social exclusion and wellbeing in Melbourne - preliminary results. Transport Policy, 16(3), 97-105.

Currie, G., Richardson, T., Smyth, P., Vella-Brodrick, D., Hine, J., Lucas, K., Stanley, J., Morris, J., Kinnear, R., \& Stanley, J. (2010). Investigating links between transport disadvantage, social exclusion and wellbeing in Melbourne-updated results. Research in Transportation Economics, 29(1), $287-295$.

Curtis, C. (2015). Public transport orientated development and network effects, Chapter 9. In R. Hickman, M. Givoni, D. Bonilla, \& D. Banister (Eds), An international handbook on transport and development. Cheltenham. UK: Edward Elgar.

Curtis, C., \& Scheurer, J. (2016). Planning for public transport accessibility. An international sourcebook. Oxon, UK: Routledge.

De Vos, J., Schwanen, T., Van Acker, V., \& Witlox, F. (2013). Travel and subjective wellbeing: A focus on findings, methods and future research needs. Transport Reviews, 33(4), 421-442.

Delbosc, A., \& Currie, G. (2011). The spatial context of transport disadvantage, social exclusion and wellbeing. Journal of Transport Geography, 19, 1130-1137.

Dodson, J. (2007) Transport disadvantage and Australian urban planning in historical perspective. The role of urban form and structure in shaping household accessibility, Chapter 1. In G. Currie, J. Stanley, and J. Stanley (Eds), No way to go. Transport and social disadvantage in Australian communities. Clayton, Victoria: Monash University ePress.

Dodson, J., \& Sipe, N. (2008). Shocking the suburbs. Oil vulnerability in the Australian city. Sydney, NSW: UNSW Press.

Florida, R. (2017) The new urban crisis: How our cities are increasing inequality, deepening segregation, and failing the middle class - and what we can do about it. New York: Basic Books.

Goodman, R., \& Coote, M. (2007). Sustainable urban form and the shopping center: An investigation of activity centers in Melbourne's growth areas. Urban Policy and Research, 25(1), 39-61.

Kaufmann, V. (2011). Rethinking the city: Urban dynamics and motility. Lausanne, Switzerland: EPFL Press.

Loader, C. (2013) Visualizing the changing socioeconomic landscape of Melbourne. Charting Transport [web log]. Retrieved from www.chartingtransport.com/2013/09/29/visualising-the-changingsocio-economic-landscape-of-melbourne/

Martel, A., Whitzman, C., Fincher, R., Lawther, P., Woodcock, I., \& Tucker, D. (2013). Getting to yes: Overcoming barriers to affordable family friendly housing in inner Melbourne. Sixth state of Australian Cities Conference (SOAC), Sydney, November 2013.

Newman, P., \& Kenworthy, J. (2015). The end of automobile dependence: How cities are moving beyond car-based planning. Washington, DC: Island Press.

Pink, B. (2013). Socio-economic indexes for areas (SEIFA), 2011. Retrieved from Australian Bureau for Statistics website: www.abs.gov.au

Scheurer, J., Curtis, C., \& McLeod, S. (2016). Making Melbourne's public transport network multidirectional: Can the associated accessibility boost mobilize latent potential for ridership and citybuilding? 38th Australasian Transport Research Forum (ATRF), Melbourne, November 2016.

SGS Economics and Planning. (2015). Effective job density: Comparing our cities and regions. Retrieved 
from SGS Economics and Planning website: www.sgsep.com.au/publications/effective-job-densitycomparing-our-cities-and-regions

Smyth, P. (2007). Transport: A new frontier for social policy? An historical reflection. Chapter 2. In G. Currie, J. Stanley, \& J. Stanley (Eds), No way to go: Transport and social disadvantage in Australian communities. Clayton, Victoria: Monash University ePress.

Stanley, J., \& Lucas, K. (2008). Social exclusion: What can public transport offer? Research in Transportation Economics, 22(1), 36-40. 